\title{
lonophore-Based Optical Sensor for Urine Creatinine Determination
}

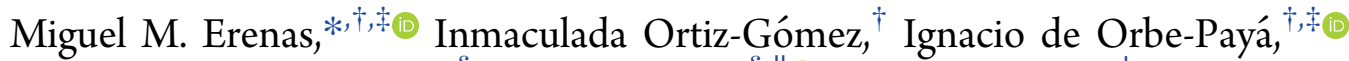 \\ Daniel Hernández-Alonso, ${ }^{\S}$ Pablo Ballester, ${ }^{\S}, \| \odot$ Pascal Blondeau, ${ }^{\perp}$ Francisco J. Andrade, ${ }^{\perp}$ \\ Alfonso Salinas-Castillo, ${ }^{\dagger, \ddagger}$ and Luis Fermín Capitán-Vallvey,
}

\begin{abstract}
${ }^{\dagger}$ ECsens, Department of Analytical Chemistry and ${ }^{\ddagger}$ Unidad de Excelencia de Química aplicada a biomedicina y medioambiente of the University of Granada Campus Fuentenueva, Faculty of Sciences, University of Granada, 18071 Granada, Spain

${ }^{\S}$ Institute of Chemical Research of Catalonia (ICIQ), The Barcelona Institute of Science and Technology, Av. Països Catalans, 16, 43007 Tarragona, Spain

"Catalan Institution for Research and Advanced Studies (ICREA), Pg. Lluís Companys 23, 08010 Barcelona, Spain

${ }^{\perp}$ Departament de Química Analítica i Química Orgànica, Universitat Rovira i Virgili (URV), C/Marcel·lí Domingo 1, 43007

Tarragona, Spain
\end{abstract}

\section{Supporting Information}

ABSTRACT: Creatinine is a metabolite present in urine, and its concentration is used to diagnose and monitor kidney performance. For that reason, the development of new sensors to analyze this metabolite and obtain accurate results in a short period of time is necessary. An optical disposable sensor for monitoring creatinine levels in urine is described. The system, based on a new aryl-substituted calix[4]pyrrole synthetic receptor, has an unusual coextraction scheme. Due to the low $\mathrm{p} K_{\mathrm{a}}$ values of creatininium $\left(\mathrm{p} K_{\mathrm{a}} 4.8\right)$, a careful selection of a lipophilic $\mathrm{pH}$ indicator that works in acid medium is required. The sensor components were optimized, and the new sensor displays a good response time to

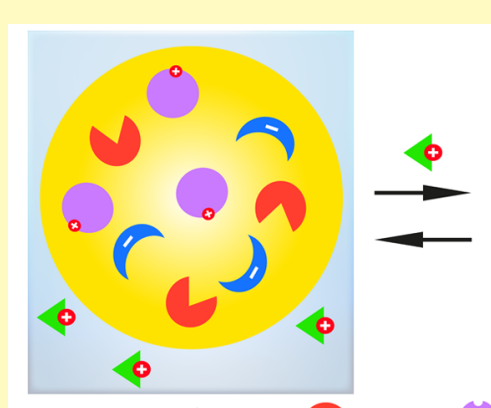

$\oplus$ Hydrogen ion $\varnothing$ Analyte Clonophore

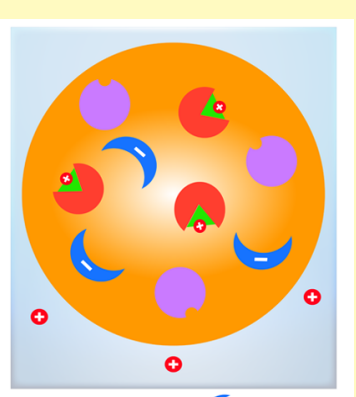

Lipophilic Indicator (Lipophilic Salt creatinine (approximately $3 \mathrm{~min}$ ) over a wide dynamic range (from $1 \times 10^{-5}$ to $1 \times 10^{-2} \mathrm{M}$ ). Moreover, the optical selectivity coefficients obtained for creatinine over common cations present in urine meet the requirements for real sample measurements. With a good sensor-to-sensor reproducibility (RSD, 5.1-6.9\% in the middle of the range), this method provides a simple, quick, cost-effective, and selective alternative to the conventional methodology based on Jaffe's reaction.

KEYWORDS: disposable sensor, host-guest chemistry, biofluids, calix[6]pyrrole, spectrometry, optode

$\mathrm{T}$ he determination of creatinine in urine and blood is among the most requested clinical tests worldwide. As a metabolic byproduct of the muscles that is toxic for the cells, creatinine must be transported by the bloodstream and eliminated through renal filtration. For this reason, the levels of creatinine in blood $\left(0.4 \times 10^{-5}-1.1 \times 10^{-5} \mathrm{M}\right)$ and urine $\left(0.3 \times 10^{-3}-2.5 \times 10^{-3} \mathrm{M}\right)$ are used by doctors to calculate the glomerular filtration rate (GFR), a value that is universally used to diagnose and monitor kidney performance. Thus, at a time when social and demographic changes are sharply increasing kidney-related conditions, ${ }^{1}$ the development of new tools for the determination of this substance is highly relevant.

The current approaches for the determination of creatinine have some important complications. Jaffe's reaction, which has been (and still is) the most used approach for more than a century, is a kinetic method with significant interferences. The same is true for bioassays, which-either by colorimetric or electrochemical detection-require the use of multiple enzymes and present some interference issues. The gold standardisotope dilution gas chromatography-is not applicable in routine assays. As a result, studies in laboratories in different countries show disappointing levels of variability with serious medical implications. ${ }^{2}$

To overcome some of these issues, alternative colorimetric and electrochemical sensors for creatinine have been proposed, but in most cases they have significant drawbacks when dealing with real samples. ${ }^{3,4}$ More recently, an ionophore for creatinine has been reported by some of us, and its application in an ionselective potentiometric sensor with the ability to quantify creatinine in urine and serum samples was demonstrated., The improvements on the limits of detection allow for sample dilution, avoiding the typical matrix interferences of real samples. These results encourage further exploration of the use of this ionophore with alternative detection schemes.

Ionophore-based optical sensors (optodes) rely on the combination of ionophores and indicators present in lipophilic

Received: November 7, 2018

Accepted: January 22, 2019

Published: January 22, 2019 
environments in different formats. ${ }^{7}$ The selective extraction of a charged analyte along with a reference ion (typically proton) either by ion-exchange, in the case of cations, or coextraction, in the case of anions, triggers the optical signal. For the most part, molecular absorption (but also molecular emission) changes in the refractive index ${ }^{8}$ or color ${ }^{9}$ are used. The signal is usually obtained under equilibrium, although kinetic conditions-with dynamic or exhaustive change ${ }^{10}$ approaches-can be used. Most of the optodes developed so far have focused on the detection of inorganic cations and, to a lesser extent, anions. Very few examples of optodes for organic ions or ionizable organic compounds have been reported, and, to the best of our knowledge, none of them have been validated with real samples. ${ }^{11-16}$ On the one hand, there are very few selective receptors for this kind of target based on host-guest chemistry. ${ }^{3,17}$ Indeed, once integrated in the sensors, the limited selectivity commonly hampers real application in biological fluids, environmental samples, and so forth. On the other hand, a challenge results from the type of signal output, i.e. the availability of indicators capable of protonation/ deprotonation at suitable $\mathrm{pH}$ conditions. Indeed, most of these systems rely on ammonium-based moieties, whose acidity constant dictates the range of $\mathrm{pH}$ working conditions. In short, the detection of organic cations with this type of indicator in acidic media is a highly challenging task. In the case of creatinine, for example, the low $\mathrm{pK}_{\mathrm{a}}$ (4.8) requires working in very unusual conditions when considering the typical ionexchange scheme for cations. At present, no such system has been characterized and reported to work with real samples.

Therefore, considering the importance of the determination of creatinine, we anticipated that the use of the novel ionophore in a system with optical detection would be highly significant. This work proposes the use of the new synthetic receptor for creatinine as ionophore in an optode. The results show the feasibility of building a new disposable device for the determination of creatinine in urine. Optimization of the analytical parameters and the signal treatment allows for the detection of creatinine with excellent sensitivity and limits of detection.

\section{EXPERIMENTAL SECTION}

Reagents and Materials. All reagents used were analytical-grade and were obtained from Sigma-Aldrich (Sigma-Aldrich Quimica S.A., Madrid, Spain). Doubly deionized water $(18.2 \mathrm{M} \Omega \mathrm{cm}$ resistance) was obtained from a Milli-RO 12 plus Milli-Q station (Millipore, Bedford, MA, USA). Aqueous creatinine standard solutions were prepared by proper dilution of a $0.5 \mathrm{M}$ stock solution of creatinine hydrochloride. Stock solutions $(1.0 \mathrm{M})$ of the following species were also used: $\mathrm{K}^{+}, \mathrm{Na}^{+}, \mathrm{NH}_{4}{ }^{+}$as chlorides. Acetic acid/sodium acetate buffer $(0.1 \mathrm{M})$ at different $\mathrm{pH}$ values was prepared from acetic acid and $\mathrm{NaOH}$. $\mathrm{HCl}(0.1 \mathrm{M})$ was used for the activation of the membranes. Poly(vinyl chloride) (PVC; high molecular weight), $4^{\prime}, 5^{\prime}$-dibromofluorescein octadecyl ester (ETH7075), o-nitrophenyl octyl ether (NPOE), potassium tetrakis[3,5-bis(trifluoromethyl)phenyl]borate (KTFPB), tridodecylmethylammonium chloride (TDMAC), and tetrahydrofuran (THF) purchased from SigmaAldrich were used to make the sensing film. The ionophore calix[4] pyrrole (Figure S1) for creatinine was synthesized in our laboratories. $^{5}$

Instruments and Software. Sensing membranes were prepared by spin-coating using WS-400Bz-6NNP/LITE equipment from Laurell Technologies Corporation (PA, USA). The characterization of the creatinine-selective sensing membranes was done with a Hewlett-Packard diode array spectrophotometer (model 8453; Norwalk, CT, USA). The film thickness of membranes was measured with the Dektak XT Stimulus Surface Profiling System contact profilometer (Bruker Corporation, Coventry, UK).

Membrane Preparation. The membrane cocktail was prepared from a batch of $31.9 \mathrm{mg}(31.5 \mathrm{wt} \%)$ of PVC, $63.9 \mathrm{mg}$ (63.0 wt \%) of NPOE, $3.2 \mathrm{mg}(3.2 \mathrm{wt} \%)$ of ionophore, $0.9 \mathrm{mg}$ (0.9 wt \%) of ETH7075, and $1.5 \mathrm{mg}(1.5 \mathrm{wt} \%)$ of KTFPB all dissolved in $1 \mathrm{~mL}$ of freshly distilled THF. KTFPB was selected because it is a noncompetitive counterion for the creatininium cation. ${ }^{5}$

The sensing membranes were casted by dropping $15 \mu \mathrm{L}$ of cocktail on a $14 \mathrm{~mm} \times 40 \mathrm{~mm} \times 0.5 \mathrm{~mm}$ thick polyester sheet on the spincoating device spinning at $190 \mathrm{rpm}$. Then, the membranes were dried in THF atmosphere. The sensing layer appears as a solid and homogeneous yellow circular film $10 \mathrm{~mm}$ diameter and $4 \mu \mathrm{m}$ thick and contains $37.1 \mathrm{mmol} \cdot \mathrm{kg}^{-1}$ in ionophore, $12.4 \mathrm{mmol} \cdot \mathrm{kg}^{-1}$ lipophilic $\mathrm{pH}$ indicator, and $17.4 \mathrm{mmol} \cdot \mathrm{kg}^{-1}$ lipophilic salt. After these membranes are dried, they are ready to be used.

Measurement Setup. The membrane is first activated by immersion in a $0.1 \mathrm{M} \mathrm{HCl}$ solution for $3 \mathrm{~min}$, acquiring a yellow color (due to the positively charged species of ETH7075), and then is immersed in a $0.01 \mathrm{M}$ acetic acid/acetate buffer at $\mathrm{pH} 3.8$ for $3 \mathrm{~min}$. After this step, the absorbance $\left(A_{\mathrm{H}_{2}{ }^{+}}\right)$at $455 \mathrm{~nm}$ is measured. Thereafter, the membrane is equilibrated for $3 \mathrm{~min}$ with standards or sample solution containing creatinine containing $0.01 \mathrm{M}$ acetic acid/ acetate buffer $\mathrm{pH} 3.8$, and the absorbance $\left(A_{\mathrm{x}}\right)$ at the same wavelength is measured again. Finally, the membrane is introduced in $0.05 \mathrm{M}$ creatinine solution containing $0.01 \mathrm{M}$ acetic acid/acetate buffer $\mathrm{pH} 3.8$ for $3 \mathrm{~min}$ to obtain the limiting absorbance $\left(A_{\mathrm{HI}}\right)$ of the neutral form (orange color) of the indicator. All these measurements were carried out at room temperature.

The extent of creatinine recognition is measured by the degree of protonation of the $\mathrm{pH}$ indicator $(1-\alpha)$. Since the indicator can exist in three forms $\left(\mathrm{H}_{2} \mathrm{I}^{+}, \mathrm{HI}\right.$, and $\left.\mathrm{I}^{-}\right)$but the recognition process only involves the positively charged $\left(\mathrm{H}_{2} \mathrm{I}^{+}\right)$and neutral $(\mathrm{HI})$ forms, an experimental value $\left(1-\alpha_{\text {eff }}\right)$ was used instead. Under the working conditions ( $\mathrm{pH} 3.8$ ), $1-\alpha_{\text {eff }}$ can be calculated from the absorbance values measured at $455 \mathrm{~nm}$ of membranes equilibrated in buffer $\left(A_{\mathrm{H}_{2} \mathrm{I}^{+}}\right)$, in $5 \times 10^{-2} \mathrm{M}$ creatinine $\left(A_{\mathrm{HI}}\right)$ solution, and in creatinine sample or standard $\left(A_{x}\right)$ according to eq 1 .

$$
1-\alpha_{\text {eff }}=\frac{A_{\mathrm{x}}-A_{\mathrm{HI}}}{A_{\mathrm{H}_{2} \mathrm{I}^{+}}-A_{\mathrm{HI}}}
$$

Analysis of Real Samples. Urine samples were obtained from healthy volunteers and were filtered before analysis. In order to evaluate the interferences and the matrix effects, samples were diluted at $1: 50 ; 1: 100 ; 1: 150$, and 1:200 ratios with the working buffer solution and measured in triplicate, selecting 1:150 dilution for creatinine determination in urine. The creatinine level predicted from the optode membrane was compared to that of Jaffe's method used as a reference. ${ }^{18}$

\section{RESULTS AND DISCUSSION}

The sensing mechanism of this system is based on a hostguest interaction, where the creatininium ion is recognized by the ionophore present in the membrane and-to preserve the electroneutrality-a proton is exchanged with the lipophilic $\mathrm{pH}$ indicator (HI), producing a change on the absorption spectrum. Thus, HI acts as an optical transducer of the recognition event. Since the $\mathrm{p} K_{\mathrm{a}}$ of creatinine is around $4.8,{ }^{19,20}$ the $\mathrm{pH}$ of the solution must be well below this value to maximize the concentration of the creatininium ion. Therefore, beyond the lipophilicity, the $\mathrm{pH}$ indicator must also have a $\mathrm{p} K_{\mathrm{a}}$ value low enough to work under these acidity conditions. For this reason, ETH7075 was selected as indicator, since it can show both acidic and basic properties ${ }^{21,22}$ and has a lower $\mathrm{p} K_{\mathrm{a}}$ value than other lipophilic $\mathrm{pH}$ indicators. ${ }^{23}$ With the incorporation of ionic sites of different charges in the 


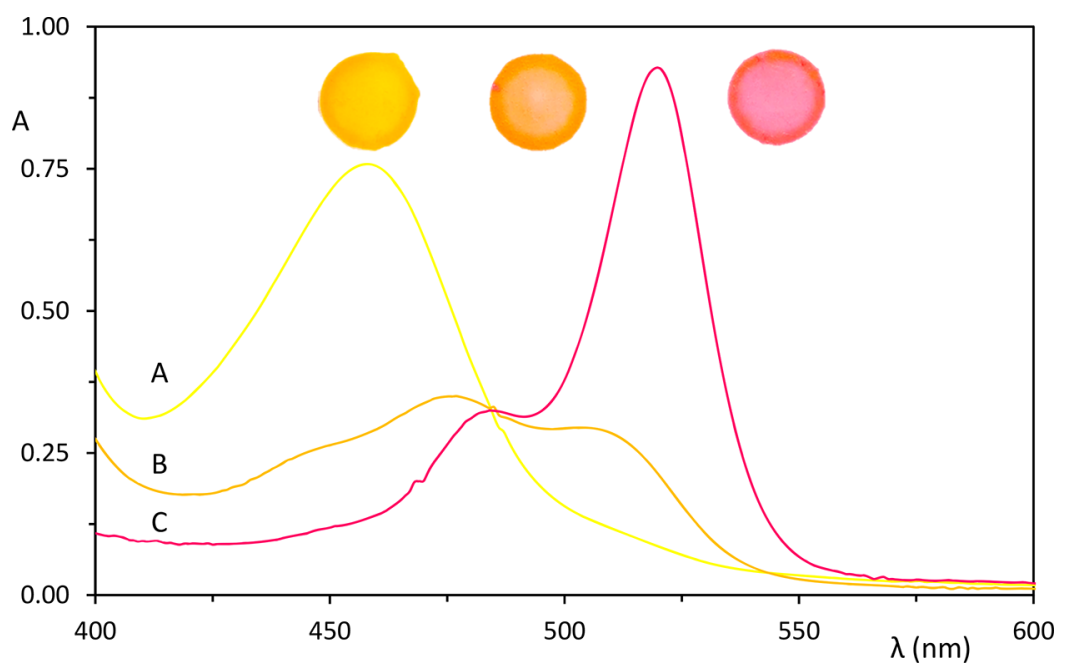

Figure 1. Absorption spectra of PVC-NPOE membranes containing $4^{\prime}, 5^{\prime}$-dibromofluorescein octadecyl ester (ETH7075). A: Membrane with ionophore (3.2 wt \%) and KTFPB (1.5 wt \%) after equilibration with $0.1 \mathrm{M} \mathrm{HCl}$; B: Same membrane after equilibration with $50 \mathrm{mM}$ creatinine in pH 3.8 buffer; C: Membrane with ionophore (3.2 wt \%) and TDMAC (0.9 wt \%) after equilibration with $0.1 \mathrm{M} \mathrm{NaOH}$.

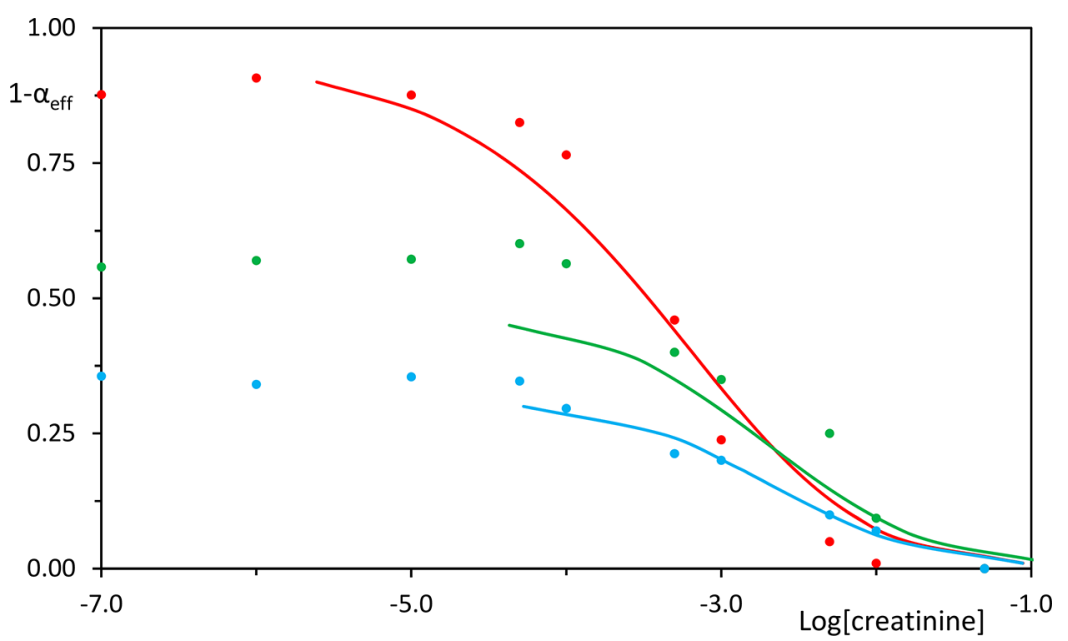

Figure 2. Theoretical model and experimental data $(n=3)$ obtained using different molar ratios of L:HI:R $\mathrm{R}^{-}: 3: 1: 1$ (red data), 3:2:1 (green data), and 3:3:1 (blue data).

membrane, such as tetraphenyl borate or quaternary ammonium salts, positively charged $\mathrm{H}_{2} \mathrm{I}^{+}$(yellow color membrane) or negatively charged $\mathrm{I}^{-}$species of the indicator (pink color membrane) can be generated (Figure 1). In this work, the inclusion of tetraphenyl borate salt in the membrane makes the equilibrium between $\mathrm{H}_{2} \mathrm{I}^{+}$and $\mathrm{HI}$ (yellow and orange membrane colors, respectively) possible.

Assuming that the membrane contains (indicated as barred species) the ionophore $(\mathrm{L})$, the $\mathrm{pH}$ indicator $\left(\mathrm{H}_{2} \mathrm{I}^{+}\right)$, and the lipophilic anion $\left(\mathrm{R}^{-}\right)$, the reaction with creatininium ions $\left(\mathrm{HC}^{+}\right)$in solution proceeds to form the $\mathrm{HCL}_{p}^{+}$complex with $p$ stoichiometry, as represented in eq 2 :

$$
\overline{\mathrm{pL}}+\overline{\mathrm{H}_{2} \mathrm{I}^{+}}+\overline{\mathrm{R}^{-}}+\mathrm{HC}^{+} \leftrightarrow \overline{\mathrm{HI}}+\overline{\mathrm{HCL}_{\mathrm{p}}^{+}}+\overline{\mathrm{R}^{-}}+\mathrm{H}^{+}
$$

The experimental parameter used to describe the behavior of the sensor is the deprotonation degree $\alpha\left([\mathrm{HI}] / I_{\mathrm{C}}\right)$ measured by the normalized absorbance measured at $455 \mathrm{~nm}$. Through an ion-exchange constant $K_{\text {exch }}$ this $1-\alpha_{\text {eff }}$ experimental value is related to the analytical concentrations of ionophore $C_{\mathrm{L}}, \mathrm{pH}$ indicator $C_{\mathrm{I}}$, and lipophilic salt $C_{\mathrm{R}}$ as well as the activities of creatininium and $\mathrm{H}^{+}$in aqueous medium according to eq $3 .{ }^{8}$

$$
K_{\mathrm{exch}}=\frac{1}{a_{\mathrm{HC}^{+}}}\left(\frac{a_{\mathrm{H}^{+}} \cdot \alpha_{\mathrm{eff}}}{1-\alpha_{\mathrm{eff}}}\right) \frac{C_{\mathrm{R}}-\left(1-\alpha_{\mathrm{eff}}\right) C_{\mathrm{I}}}{\left(C_{\mathrm{L}}-p\left(C_{\mathrm{R}}-\left(1-\alpha_{\mathrm{eff}}\right) C_{\mathrm{I}}\right)\right)^{p}}
$$

The ionophore used in this work is an aryl-substituted monophosphonate-bridged calix[4]pyrrole (L), recently reported by some of us as a creatininium receptor. It includes a functionalized aromatic polar cavity that allows for multiple host-guest interactions with a creatininium ion based on hydrogen-bonding, $\mathrm{CH}-\pi, \pi-\pi$, and hydrophobic interactions resulting in a good fit considering the size and bond complementarity. 5,6

Optimization of the Response. Membrane Optimization. An ionophore:lipophilic salt molar ratio $\left(\mathrm{L}: \mathrm{R}^{-}=3: 1\right)$ previously established in the study of the potentiometric sensor $^{6}$ was initially used. First, the influence of the $\mathrm{pH}$ indicator (HI) was studied. Membrane cocktails with L:HI: ${ }^{-}$ molar ratios of $3: 1: 1,3: 2: 1$, and $3: 3: 1$ were evaluated. The results show that an excess $\mathrm{HI}: \mathrm{R}^{-}$ratio reduces the linear 


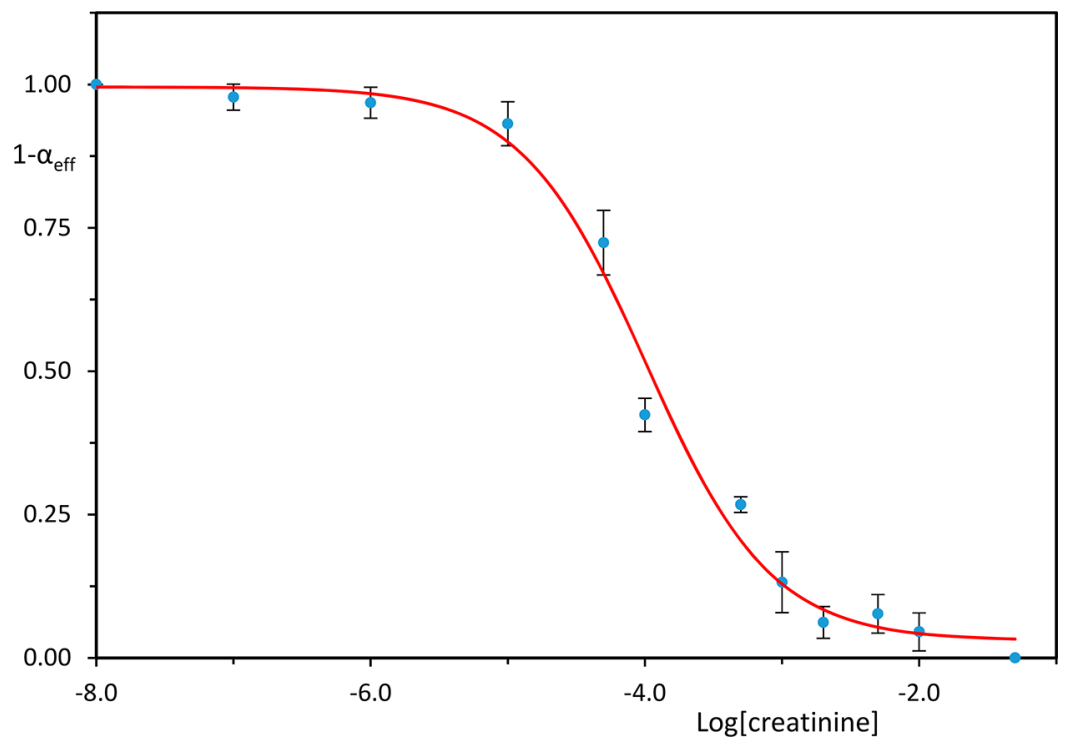

Figure 3. Calibration function of creatinine sensing membrane $(n=3)$.

range, although the limit of detection (LOD) remains constant around $6 \times 10^{-5} \mathrm{M}$ (Figure 2).

After this, different lipophilic salt molar ratios, namely, 3:1:1, $3: 1: 1.25,3: 1: 1.5$, and $3: 1: 1.75$ (L:HI:R ${ }^{-}$), were tested (Figures S2-S5). A 3:1:1.5 molar ratio gives the best results in terms of LOD $\left(1 \times 10^{-5} \mathrm{M}\right)$ compared to the other compositions.

Once the chromoionophore:lipophilic salt ratio is optimized and considering that the theoretical model predicts an increase in sensitivity with ionophore concentration, cocktails from 3:1:1.5 to $5: 1: 1.5$ (L:HI:R ${ }^{-}$) were tested (Figure S6). Results shows an improvement in sensitivity around $10 \%$ in the best case that does not justify the considerable increase in calix [6]pyrrole ionophore consumption, the reason as to why the $3: 1: 1.5$ ratio was maintained.

In this way, the optimized sensing membrane was prepared from a cocktail including $3.2 \mathrm{mg}$ of ionophore, $1.5 \mathrm{mg}$ of KTFPB, $0.9 \mathrm{mg}$ of ETH 7075, $63.9 \mathrm{mg}$ of NPOE, and $31.9 \mathrm{mg}$ of PVC in $1 \mathrm{~mL}$ of freshly distilled THF. The circular membrane prepared by spin-coating at $190 \mathrm{rpm}$ is $4 \mu \mathrm{m}$ thick across the membrane surface (Figure S7).

Reaction Parameters. One characteristic of ionophorebased optical sensors that include a $\mathrm{pH}$ indicator in the membrane is $\mathrm{pH}$ cross-sensitivity due to cations with a competitive ion-exchange process. In this work, the $\mathrm{pH}$ must be low enough to displace the equilibrium toward the generation of the creatininium ion. Thus, to study the influence of the $\mathrm{pH}$, two experiments were performed using membranes equilibrated in a set of $0.01 \mathrm{M}$ acetic acid/acetate buffers of different $\mathrm{pH}$ 's containing a constant concentration of $0.1 \mathrm{mM}$ creatinine in one case and without it in the other. In the absence of creatinine (Figure S8B), the absorbance at 455 $\mathrm{nm}$ corresponding to $\mathrm{H}_{2} \mathrm{I}^{+}$species is constant until a $\mathrm{pH}$ around 4 and then decreases by deprotonation. In the presence of creatinine (Figure S8A), the absorbance decreases until 4.25 and remains constant thereafter. $\mathrm{A} \mathrm{pH}=3.8$ was chosen as the optimum value, since the indicator is still completely in its cationic form and most of the creatinine is protonated (creatininium fraction at this $\mathrm{pH}$ of $90.9 \%$, Figure S8C). Thus, at this $\mathrm{pH}$, the signal only depends on the presence of creatininium.
The nearly constant value of absorbance from $\mathrm{pH} 4.25$ onward in the presence of creatinine can be explained by the combination of two opposite effects: the reduction of the ionexchange due to the reduction in the amount of creatininium present and the displacement of the $\mathrm{pH}$ indicator equilibrium. ${ }^{21,22}$ The selected $\mathrm{pH}$ (3.8) is in good agreement with the working $\mathrm{pH}$ used for the potentiometric sensor based on the same ionophore. ${ }^{6}$

In order to evaluate the stoichiometry of ionophore:creatinine, the fit of experimental data with eq 2 for stoichiometric index $p$ of $0.5,1$, and 2 was studied. The effect of the stoichiometry on the theoretical response curve is small, except for $p=2$, hindering a clear distinction between 0.5 and 1 stoichiometric index. Additionally, the summation of residual squares (srs) for the adjustment of experimental data to each theoretical model (eq 3 ) ( $p: 1$; srs: $0.44 ; p: 2$; srs: $0.85 ; p$ : 0.5 ; srs: 0.42 ) does not help to solve this issue. This difficulty evaluating the stoichiometry for the ionophore:creatinine complex has also appeared when studying the potentiometric sensor for creatinine based on the same ionophore. ${ }^{6}$ The fit by least-squares of the experimental data in the maximum slope zone of the response curve makes it possible to calculate a value of $0.7 \pm 0.3$ for $K_{\text {exch }}$, which suggests a 1:1 stoichiometry.

Analytical Characterization. The response of the ionophore-based optical sensors has the usual sigmoidal shape adjusting the data set to a Boltzmann (eq 4) where $A_{1}$ and $A_{2}$ represent the initial and final value, $A_{3}$ is the inflection point, and $A_{4}$ is the width. The fit of the experimental data to the Boltzmann equation provides a $R^{2}=0.987$, as shown in Figure 3. The calculated limit of detection is $1 \times 10^{-5} \mathrm{M}$, obtained as the intersection of the linear calibration function adjusted in the maximum slope zone and a linear function adjusted in the minimum slope zone at low analyte concentration (Table 1 ).

$$
1-\alpha_{\text {eff }}=\frac{A_{1}-A_{2}}{1+e^{\log [\text { creatinine }]-A_{3} /\left(A_{4}\right)}}+A_{2}
$$

The reproducibility of the measurement was evaluated at two different creatinine concentrations, located in the maximum slope zone of the calibration function, $5 \times 10^{-4} \mathrm{M}$ and $5 \times$ $10^{-5} \mathrm{M}$. Coefficients of variation of 5.1 and $6.9 \%(n=5)$ were obtained, respectively. 
Table 1. Analytical Parameters of the Sensing Membrane for Creatinine Determination

\begin{tabular}{lc}
\multicolumn{2}{c}{ analytical parameters } \\
\multicolumn{3}{c}{ Boltzmann equation $($ see eq 4$)$} \\
$A_{1}$ & 0.996 \\
$A_{2}$ & 0.030 \\
$A_{3}$ & -3.990 \\
$A_{4}$ & 0.457 \\
$R^{2}$ & 0.986 \\
limit of detection & $1 \times 10^{-5} \mathrm{M}$ \\
dynamic range & $1 \times 10^{-5}-1 \times 10^{-2} \mathrm{M}$ \\
\multicolumn{2}{c}{ intermembrane precision $(n=5)$} \\
$5 \times 10^{-4} \mathrm{M}$ & $5.1 \%$ \\
$5 \times 10^{-5} \mathrm{M}$ & $6.9 \%$ \\
\end{tabular}

The influence of different interfering species typically found in urine was studied using the separate solutions method. This method is typically used to study selectivity in this type of sensors, ${ }^{8}$ and it is carried out obtaining a calibration for each interfering considered (Figure S10), obtaining the $K_{\text {exch }}$ for each one. Finally, eq $\mathrm{S} 1$ is applied to obtain the $\log K_{\mathrm{C}, \mathrm{j}}$ for creatinine and the considered interfering, being this value is a measurement of the difference between the $K_{\text {exch }}$ of the analyte and the interfering. Seven different interfering solutions containing different concentrations of interfering species from $1 \times 10^{-6}$ to $0.1 \mathrm{M}$ were tested. The $K_{\text {exch }}$ calculated for interferents (Table 2) is, at least, 3 orders of magnitude lower

Table 2. $K_{\text {exch }}$ Selectivity as $\log K_{\text {creatinine, }}$ Calculated Using the Separated Solution Method and $P_{\text {creatinine,j }}$ Required for the Interferents Present in Urine at Different Tolerable Errors $(1,10$, and 100\%)

\begin{tabular}{lccccc} 
& & & \multicolumn{3}{c}{ required $P_{\text {creatinine, }}$} \\
\cline { 4 - 6 } interfering & $K_{\text {exch }}$ & $\log K_{\text {creatinine, }}$ & $1 \%$ & $10 \%$ & $100 \%$ \\
$\mathrm{~K}^{+}$ & $7.0 \times 10^{-4}$ & -3.0 & -3.3 & -2.3 & -1.3 \\
$\mathrm{Na}^{+}$ & $2.5 \times 10^{-4}$ & -3.4 & -3.6 & -2.6 & -1.6 \\
$\mathrm{NH}_{4}^{+}$ & $2.9 \times 10^{-5}$ & -4.4 & -2.6 & -1.6 & -0.6 \\
creatine & $2.9 \times 10^{-6}$ & -5.4 & & & \\
\hline
\end{tabular}

than that obtained for creatinine (0.7). This indicates that the selectivity coefficient obtained by the separate solution method in terms of $\log K_{\mathrm{C}, \mathrm{j}}$ is always lower than -3 . Finally, considering that the maximum tolerable error $\left(P_{\mathrm{IJ}}\right)$ in urine is around $10 \%,{ }^{24}$ the required selectivity coefficient for 1,10 , and $100 \%$ was calculated (Table 2). In the case of $\mathrm{K}^{+}$and $\mathrm{Na}^{+}$, the error is under $10 \%$, and in the case of $\mathrm{NH}_{4}{ }^{+}$and creatine it is even below $1 \%$. The selectivity coefficients found for $\mathrm{K}^{+}$and $\mathrm{Na}^{+}$are similar to the ones found by the same ionophore in an ISE, ${ }^{6}$ but in the case of $\mathrm{NH}_{4}^{+}$and creatine, the selectivity coefficients are better when using the same ionophore included in an optode.

Additionally, we studied the potential interference of other compounds usually present in urine as are aspartic and glutamic acids. In both cases we found no answer at their maximum physiological value in urine $\left(1-\alpha_{\text {eff }}=0.91\right.$ for $2 \times$ $10^{-3} \mathrm{M}$ in aspartic acid and $1-\alpha_{\text {eff }}=0.99$ for $2 \times 10^{-3} \mathrm{M}$ in glutamic acid). We attribute the selectivity of the sensing membrane toward creatinine due to both the calix[4]pyrrole ionophore and the permselectivity of the membrane by including an anionic lipophilic salt. At the working $\mathrm{pH}$ both aspartic and glutamic acids have negative net charge.
A comparison table of recently developed creatinine determination methods (see Table S1) shows some analytical parameters, as well as types of measurement and recognition. We observe that the detection limit and dynamic range are similar to other methods previously published, are mainly electrochemical methods, and, in terms of response time, permit a faster analysis than other optical methods.

Analysis of Real Samples. The direct analysis of urine samples is affected by unspecific interferences. Thus, considering the good sensitivity of the proposed sensor, the influence of the dilution factor on the prediction of creatinine was studied. Optimum values for 1:150 dilution factors were found (Table S2), since lower dilutions (1:50 and 1:100) affect the predicted values due to the matrix effect and higher dilution (1:200) makes the creatinine concentration too low and out of the dynamic range of the sensor. Analysis of real urine samples yields recovery values from 81 to $112 \%$ (Table 3 ). High creatinine concentration values were tested by spiking samples at the $15 \mathrm{mM}$ level, obtaining recoveries in the range of 85 to $113 \%$ (Table S3).

Table 3. Determination of Creatinine in Urine Samples Using the Sensor and Reference Methods $(n=3)$

$\begin{array}{cccc}\text { sample } & \text { sensor } \mathrm{mM} & \text { reference } \mathrm{mM} & \text { recovery }(\%) \\ 1 & 6.3 \pm 0.2 & 5.5 \pm 0.2 & 114 \\ 2 & 6.1 \pm 0.3 & 7.5 \pm 0.3 & 81 \\ 3 & 1.9 \pm 0.3 & 1.7 \pm 0.1 & 112 \\ 4 & 4.5 \pm 0.4 & 4.1 \pm 0.1 & 110\end{array}$

\section{CONCLUSION}

This work reports on the implementation of a calix[4]pyrrole ionophore for the optical detection of creatinine in disposable format, being one of the first creatinine optical sensing membranes based on a ionophore-chromoionophore scheme. The sensing membrane components as well as the working $\mathrm{pH}$ were first optimized to establish a suitable analytical performance. The sensor selectivity was assessed considering the common cations and species present in urine, and the obtained coefficients allowed for a maximum tolerable error between 1 and $10 \%$. Based on the results in buffer, real sample measurements were achieved by proper dilution, making suitable recovery for biofluid detection possible. With the development of low-cost optical sensors based on paper and integration with a smartphone reader, the system developed here provides new opportunities as a decentralized analytical platform. $^{25}$

\section{ASSOCIATED CONTENT}

\section{Supporting Information}

The Supporting Information is available free of charge on the ACS Publications website at DOI: 10.1021/acssensors.8b01378.

Additional data related to membrane optimization and thickness, response time of sensing membrane, selectivity study and maximum tolerable error, comparison with other creatinine methods described in literature (PDF)

\section{AUTHOR INFORMATION}

\section{Corresponding Author}

*E-mail: erenas@ugr.es. 


\section{ORCID $\odot$}

Miguel M. Erenas: 0000-0002-5616-1749

Ignacio de Orbe-Payá: 0000-0003-2308-6241

Pablo Ballester: 0000-0001-8377-6610

\section{Notes}

The authors declare no competing financial interest.

\section{ACKNOWLEDGMENTS}

This study was supported by projects from the Spanish MINECO (CTQ2016-78754-C2-1-R). The project was partially supported by the European Regional Development Funds (ERDF). In addition, the URV team would like to acknowledge financial support from the Spanish Ministry of Economy and Competitiveness and European Regional Development Fund (ERDF) CTQ2016-77128-R Project. The ICI team would also like to thank the Gobierno de España MINECO (projects CTQ2017-84319-P and Severo Ochoa Excellence Accreditation 2014-2018 SEV-2013-0319), FEDER funds (Project CTQ2017- 84319-P), and the CERCA Programme/Generalitat de Catalunya and AGAUR (2017 SGR 1123) for funding.

\section{REFERENCES}

(1) Bello, A. K.; Levin, A.; Tonelli, M.; Okpechi, I. G.; Feehally, J.; Harris, D.; Jindal, K.; Salako, B. L.; Rateb, A.; Osman, M. A.; Qarmi, B.; Saab, S.; Lunney, M.; Wiebe, N.; Ye, F.; Johnson, D. W. Global Kidney Health Atlas: A report by the International Society of Nephrology on the current state of organization and structures for kidney care across the globe; International Society of Nephrology: Brussels, Belgium, 2017.

(2) Delanghe, J. R.; Cobbaert, C.; Galteau, M.; Harmoinen, A.; Jansen, R.; Kruse, R.; Laitinen, P.; Thienpont, L. M.; Wuyts, B.; Weykamp, C.; Panteghini, M. Trueness verification of actual creatinine assays in the European market demonstrates a disappointing variability that needs substantial improvement. An international study in the framework of the EC4 creatinine standardization working group. Clin. Chem. Lab. Med. 2008, 46, 1319-1325.

(3) Bühlmann, P.; Simon, W. Neutral hosts for the complexation of creatinine. Tetrahedron 1993, 49 (35), 7627-7636.

(4) Elmosallamy, M. A. F. New potentiometric sensors for creatinine. Anal. Chim. Acta 2006, 564 (2), 253-257.

(5) Guinovart, T.; Hernandez-Alonso, D.; Adriaenssens, L.; Blondeau, P.; Martinez-Belmonte, M.; Rius, F. X.; Andrade, F. J.; Ballester, P. Recognition and Sensing of Creatinine. Angew. Chem., Int. Ed. 2016, 55 (7), 2435-2440.

(6) Guinovart, T.; Hernandez-Alonso, D.; Adriaenssens, L.; Blondeau, P.; Rius, F. X.; Ballester, P.; Andrade, F. J. Characterization of a new ionophore-based ion-selective electrode for the potentiometric determination of creatinine in urine. Biosens. Bioelectron. 2017, $87,587-592$.

(7) Xie, X.; Bakker, E. Ion selective optodes: from the bulk to the nanoscale. Anal. Bioanal. Chem. 2015, 407 (14), 3899-3910.

(8) Bakker, E.; Bühlmann, P.; Pretsch, E. Carrier-Based Ion-Selective Electrodes and Bulk Optodes. 1. General Characteristics. Chem. Rev. 1997, 97, 3083-3132.

(9) Erenas, M. M.; de Orbe-Paya, I.; Capitan-Vallvey, L. F. Surface Modified Thread-Based Microfluidic Analytical Device for Selective Potassium Analysis. Anal. Chem. 2016, 88 (10), 5331-5337.

(10) Mistlberger, G.; Crespo, G. A.; Bakker, E. Ionophore-based optical sensors. Annu. Rev. Anal. Chem. 2014, 7, 483-512.

(11) Cash, K. J.; Clark, H. A. In vivo histamine optical nanosensors. Sensors 2012, 12, 11922-11932.

(12) Chan, W. H.; Lee, A. W. M.; Wang, K. Design of a primary amine-selective optode membrane based on lipophilic hexaester of calix[6]arene. Analyst 1994, 119, 2809-2812.
(13) Choi, M. M. F.; Wu, X. J.; Li, Y. R. Optode Membrane for Determination of Nicotine via Generation of Its Bromoethane Derivative. Anal. Chem. 1999, 71 (7), 1342-1349.

(14) Choi, M. M. F.; Chung, K. O. P.; Wu, X. Nicotine derivative optode membrane with nonactin as ionophore. Talanta 2002, 56 (6), 1027-1038.

(15) He, H.; Uray, G.; Wolfbeis, O. S. Enantioselective Optodes. Anal. Chim. Acta 1991, 246, 251-257.

(16) Holy, P.; Morf, W. E.; Seller, K.; Simon, W.; Vigneron, J. P. Enantioselective Optode Membranes with Enantiomer Selectivity for (R)- and (S)-1-Phenylethylammonium Ions. Helv. Chim. Acta 1990, 73 (5), 1171-1181.

(17) Bell, T. W.; Hou, Z.; Luo, Y.; Drew, M. G.; Chapoteau, E.; Czech, B. P.; Kumar, A. Detection of creatinine by a designed receptor. Science 1995, 269 (5224), 671-674.

(18) Pizzolante, J. M. Stabilized alkaline picrate reagent for Jaffe creatinine determination. US4818703A, Apr 4, 1989.

(19) Gao, J.; Hu, Y.; Li, S.; Zhang, Y.; Chen, X. Tautomeric equilibrium of creatinine and creatininium cation in aqueous solutions explored by Raman spectroscopy and density functional theory calculations. Chem. Phys. 2013, 410 (Supplement C), 81-89.

(20) Grzybowski, A. K.; Datta, S. P. 31. The ionisation constant of the protonated form of creatinine. J. Chem. Soc. 1964, No. 0, 187196.

(21) Mi, Y.; Green, C.; Bakker, E. Polymeric Membrane pH Electrodes Based on Electrically Charged Ionophores. Anal. Chem. 1998, 70 (24), 5252-5258.

(22) Mi, Y.; Bakker, E. Lipophilic Ionic Sites for Solvent Polymeric Membrane $\mathrm{pH}$ Electrodes Based on 4',5'-Dibromofluorescein Octadecylester as Electrically Charged Carrier. J. Electrochem. Soc. 1997, 144 (2), L27-L28.

(23) Qin, Y.; Bakker, E. Quantitive binding constants of $\mathrm{H}$ t-selective chromoionophores and anion ionophores in solvent polymeric sensing membranes. Talanta 2002, 58 (5), 909-918.

(24) Oesch, U.; Ammann, D.; Simon, W. Ion-selective membrane electrodes for clinical use. Clin. Chem. 1986, 32 (8), 1448-1459.

(25) Lopez-Ruiz, N.; Curto, V. F.; Erenas, M. M.; Benito-Lopez, F.; Diamond, D.; Palma, A. J.; Capitan-Vallvey, L. F. Smartphone-Based Simultaneous $\mathrm{pH}$ and Nitrite Colorimetric Determination for Paper Microfluidic Devices. Anal. Chem. 2014, 86 (19), 9554-9562. 